\title{
Loss of Heterozygosity on Chromosome 10 Is More Extensive in Primary (De Novo) Than in Secondary Glioblastomas
}

\author{
Hironori Fujisawa, Rui M. Reis, Mitsutoshi Nakamura, Stefano Colella, \\ Yasuhiro Yonekawa, Paul Kleihues, and Hiroko Ohgaki
}

International Agency for Research on Cancer (HF, RMR, MN, SC, PK, HO), Lyon, France; and Department of Neurosurgery (YY), University Hospital, Zürich, Switzerland

SUMMARY: Glioblastomas develop de novo (primary glioblastomas) or through progression from low-grade or anaplastic astrocytoma (secondary glioblastomas). There is increasing evidence that these glioblastoma subtypes develop through different genetic pathways. Primary glioblastomas are characterized by EGFR and MDM2 amplification/overexpression, PTEN mutations, and p16 deletions, whereas secondary glioblastomas frequently contain p53 mutations. Loss of heterozygosity (LOH) on chromosome $10(\mathrm{LOH \# 10)}$ is the most frequent genetic alteration in glioblastomas; the involvement of tumor suppressor genes, other than PTEN, has been suggested. We carried out deletion mappings on chromosome 10, using PCR-based microsatellite analysis. $\mathrm{LOH} \# 10$ was detected at similar frequencies in primary $(8 / 17 ; 47 \%)$ and secondary glioblastomas $(7 / 13 ; 54 \%)$. The majority $(88 \%)$ of primary glioblastomas with LOH\#10 showed LOH at all informative markers, suggesting loss of the entire chromosome 10. In contrast, secondary glioblastomas with LOH\#10 showed partial or complete loss of chromosome 10q but no loss of 10p. These results are in accordance with the view that $\mathrm{LOH}$ on $10 \mathrm{q}$ is a major factor in the evolution of glioblastoma multiform as the common phenotypic end point of both genetic pathways, whereas LOH on 10p is largely restricted to the primary (de novo) glioblastoma. (Lab Invest 2000, 80:65-72).

$G$ lioblastoma (World Health Organization [WHO] Grade IV) is the most frequent and malignant human brain tumor, occurring at a frequency of two to three new cases per 100,000 population and per year for most European and North American countries (Lantos et al, 1996). Despite progress in surgery and adjuvant therapy, patients with glioblastoma still have a dismal prognosis and they usually succumb to the disease within 1 year after diagnosis (Galanis et al, 1998; Leenstra et al, 1998). Glioblastomas may develop rapidly, with a short clinical history (primary or de novo glioblastoma), or more slowly through progression from low-grade (WHO Grade II) or anaplastic (WHO Grade III) astrocytoma (secondary glioblastoma) (Kleihues and Ohgaki, 1999). These glioblastoma subtypes, although largely indistinguishable histologically, constitute distinct disease entities that manifest in different age groups and develop through different genetic pathways. Primary glioblastomas occur in older patients and are characterized by EGFR amplification/overexpression and, less frequently, MDM2 amplification, PTEN (MMAC1) mutations, and p16 homozygous deletion, while secondary glioblastomas occur in younger patients and contain p53 mutations as a genetic hallmark (Kleihues and Ohgaki, 1999).

Received October 5, 1999.

Address reprint requests to: Dr. H. Ohgaki, Unit of Molecular Pathology, International Agency for Research on Cancer, 69372 Lyon Cedex 08, France.Fax: +33472738564; E-mail:ohgaki@iarc.fr
Loss of heterozygosity ( $\mathrm{LOH}$ ) on chromosome 10 $(\mathrm{LOH \# 10)}$ is the most frequent genetic alteration in glioblastomas, reportedly occurring in up to $80 \%$ of cases (Albarosa et al, 1996; Fults et al, 1998; Ichimura et al, 1998; Karlbom et al, 1993; Kon et al, 1998; Maier et al, 1997; Rasheed et al, 1995; Sonoda et al, 1996; Voesten et al, 1997). LOH\#10 is less frequent ( 40\%) in anaplastic astrocytomas (Albarosa et al, 1996; Bijleveld et al, 1997; Ichimura et al, 1998; Karlbom et al, 1993; Kon et al, 1998; Maier et al, 1997; Rasheed et al, 1995; Sonoda et al, 1996; Voesten, 1997), and rarely occurs in low-grade astrocytomas (Ichimura et al, 1998; Karlbom et al, 1993; Kon et al, 1998; Maier et al, 1997; Rasheed et al, 1995; Sonoda et al, 1996; Voesten et al, 1997). The majority of glioblastomas appear to have lost an entire copy of chromosome 10 (Albarosa, 1996; Fults et al, 1998; Ichimura et al, 1998; Kon et al, 1998; Maier et al, 1997; Rasheed et al, 1995; Voesten et al, 1997). In glioblastomas with partial

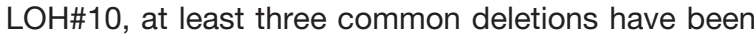
identified: (a) 10p14-pter (Ichimura et al, 1998; Karlbom et al, 1993; Kimmelman et al, 1996; Kon et al, 1998; Sonoda et al, 1996; Voesten et al, 1997); (b) 10q23-24 (Albarosa et al, 1996; Fults, et al, 1998; Ichimura et al, 1998; Karlbom et al, 1993; Maier et al, 1997; Rasheed et al, 1995; Sonoda et al, 1996); and (c) 10q25-qter (Albarosa et al, 1996; Fults et al, 1998; Ichimura et al, 1998; Karlbom et al, 1993; Maier et al, 1997; Rasheed et al, 1995; Sonoda et al, 1996), suggesting the presence of multiple tumor suppressor 
genes. LOH\#10 has been detected in $60 \%$ to $100 \%$ of glioblastomas with EGFR amplification (Lang et al, 1994; Leenstra et al, 1998; von Deimling et al, 1992) and in $40 \%$ to $80 \%$ of glioblastomas with a p53 mutation (Lang et al, 1994; Leenstra et al, 1998), suggesting that LOH\#10 is involved in the development of both primary and secondary glioblastomas.

The objective of the present study was to clarify whether the frequency and allelic patterns of LOH\#10 differ between primary and secondary glioblastomas. We carried out deletion mapping on chromosome 10, using PCR-based microsatellite analysis in 17 primary glioblastomas (using normal DNA as a reference) and 13 secondary glioblastomas which progressed from low-grade astrocytomas (using normal or low-grade astrocytoma DNA as a reference). The presence and pattern of $\mathrm{LOH \# 10} \mathrm{were} \mathrm{correlated} \mathrm{with} \mathrm{other} \mathrm{genetic}$ alterations, including EGFR amplification and p53 and PTEN mutations.

\section{Results}

\section{LOH on Chromosome 10}

Using 28 microsatellite markers, we examined a total of 840 polymorphic loci on chromosome 10 and obtained 621 (74\%) informative results. Eight (47\%) of 17 primary glioblastomas showed LOH\#10. Of these, seven $(88 \%)$ showed deletions at all informative loci; this was interpreted as the loss of an entire copy of chromosome 10. Case 294 was exceptional, with deletions at all informative loci on 10p but with none on $10 \mathrm{q}$ (Figs. 1 and 2).

In secondary glioblastomas, LOH\#10 was demonstrated in 7 of $13(54 \%)$ cases, ie, at a frequency similar to that in primary glioblastomas $(p=1.0)$. However, in all cases, deletions were partial and typically located on 10q. One glioblastoma (case 25) showed $\mathrm{LOH}$ at all informative loci on 10q. In the remaining six cases, chromosomal deletions on $10 \mathrm{q}$ were partial. One tumor (case 70) showed an additional small deletion on $10 p$ at D10S199. The most common deletion in all seven cases was on 10q25qter distal to D10S1683, covering the DMBT1 (Mollenhauer et al, 1997) and FGFR2 (Moschonas et al, 1996) loci (Fig. 1).

For three secondary glioblastomas in which lowgrade astrocytoma DNA was used as a reference, DNA from adjacent normal brain tissue (Cases 57 and 68) and peripheral blood leukocytes (Case 72) was also subjected to analysis. Allelic patterns of normal tissues and low-grade astrocytomas were concordant at all informative loci. In another case (Case 26), one of the two alleles showed significant decrease (>50\%) in signal intensity when compared with the remaining allele at markers D10S587, 1723, and 1700 (Fig. 1, marked as asterisk), which may suggest that LOH had already occurred in low-grade astrocytoma.
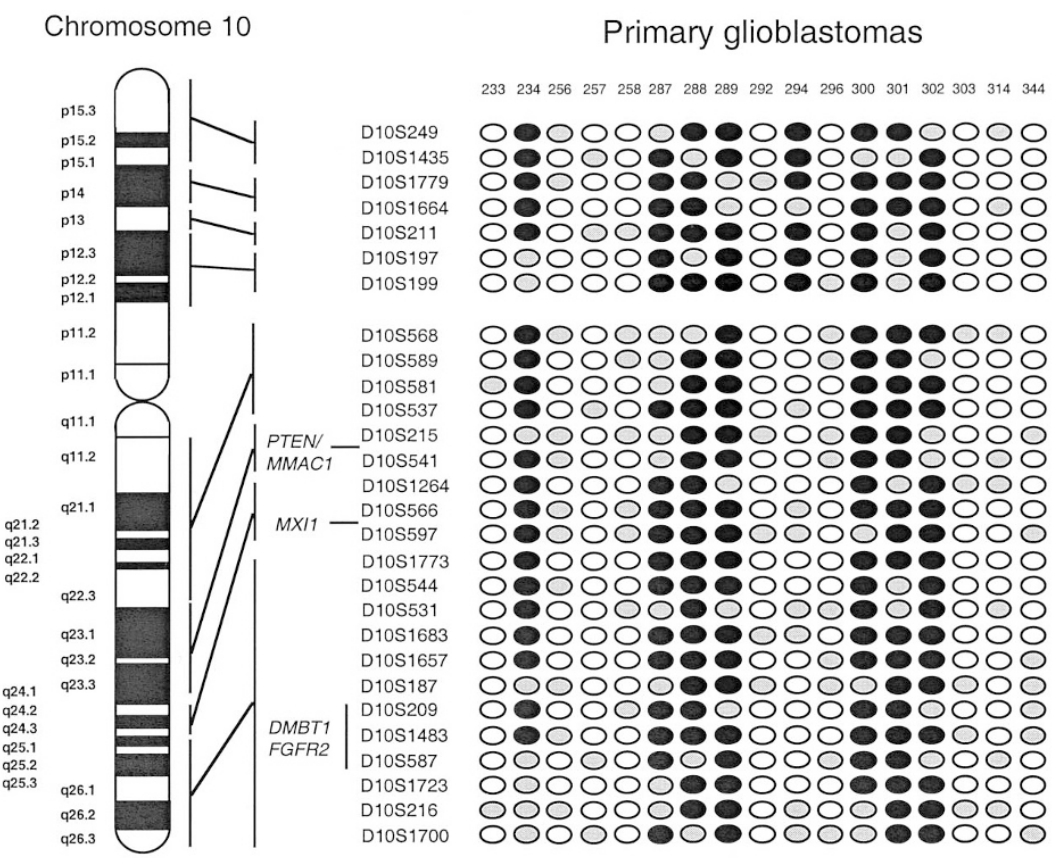

\section{Secondary glioblastomas}
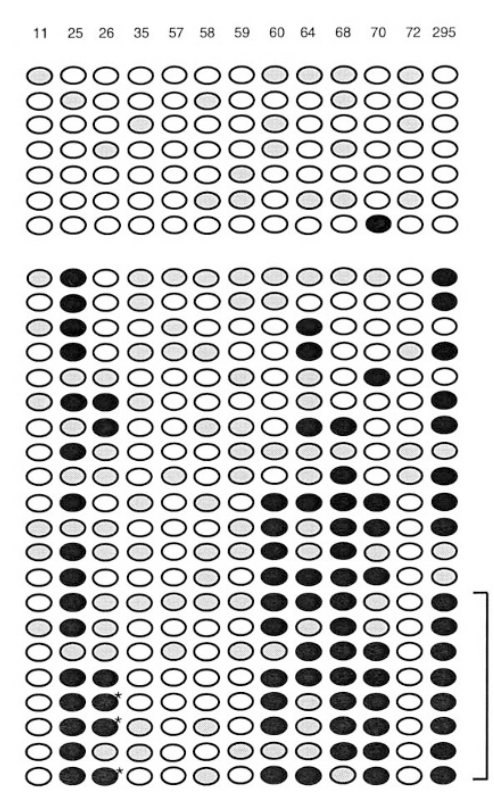

O: no LOH : LOH $O$ : non-informative

\section{Figure 1.}

Allelic patterns of chromosome 10 in 17 primary and 13 secondary glioblastomas. Case numbers are indicated at the top of each column. The overall frequency of loss of heterozygosity ( $\mathrm{LOH})$ on chromosome 10 is similar in both glioblastoma subtypes but the extent of chromosomal loss differs. Primary glioblastomas often show complete loss (10p, q) while in secondary glioblastomas, LOH is typically restricted to the long arm (10q). 


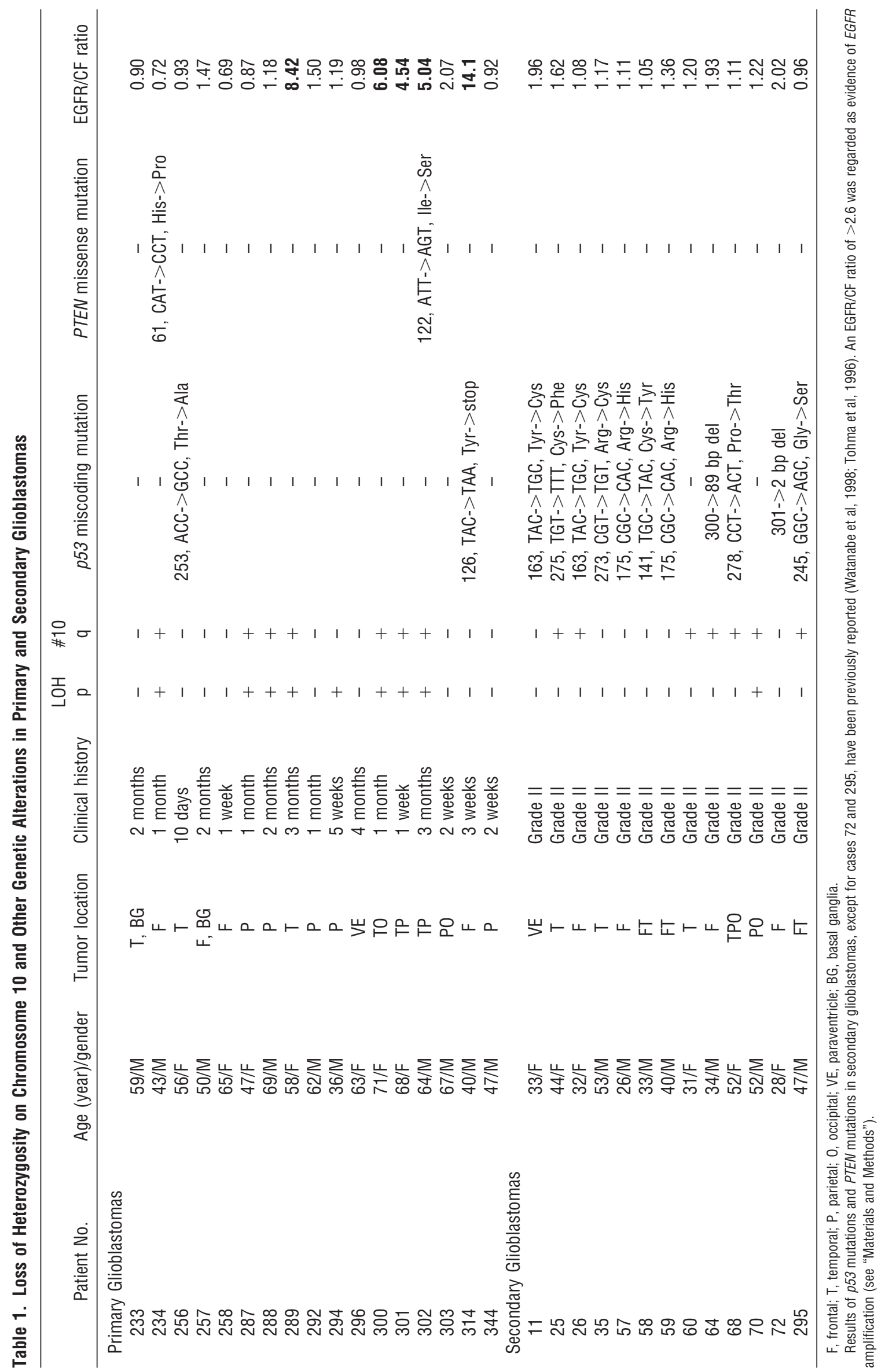




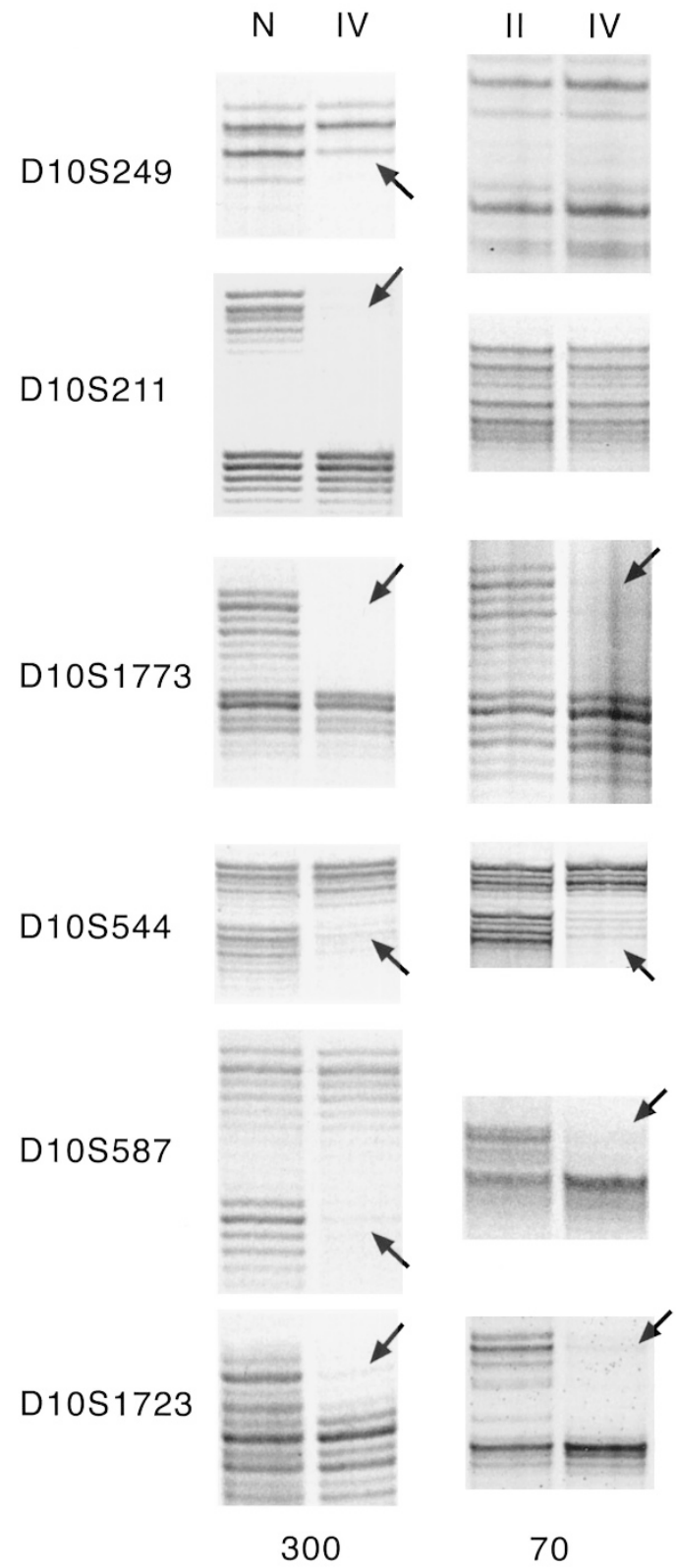

\section{Figure 2}

Representative results of loss of heterozygosity ( $\mathrm{LOH}$ ) on chromosome 10 in a primary (case 300) and a secondary (case 70) glioblastoma. Microsatellite markers are indicated on the left side of each panel. $\mathrm{LOH}$ is indicated by arrows. N, normal (blood); II, low-grade astrocytoma (World Health Organization Grade II); IV, glioblastoma (Grade IV).

\section{Correlation of LOH\#10 with Other Genetic Alterations}

PCR-SSCP, followed by DNA sequencing, demonstrated p53 missense mutations in $2(12 \%)$ of 17 primary glioblastomas and in 11 (85\%) of 13 secondary glioblastomas ( $p=0.0001$; Table 1$)$. PTEN mutations were found in $2(12 \%)$ of 17 primary glioblastomas but none in secondary glioblastomas (Table 1). EGFR amplification was detected by differential PCR in $5(29 \%)$ of 17 primary glioblastomas but in none of the secondary glioblastomas (Table 1). EGFR amplification tended to be associated with complete LOH\#10: 4 (80\%) of 5 primary glioblastomas with
EGFR amplification showed an entire loss of chromosome 10 , whereas only $3(25 \%)$ of 12 glioblastomas without EGFR amplification showed complete LOH\#10. However, this difference was not statistically significant ( $p=0.10)$. There was no significant correlation between the presence of LOH\#10 and other genetic alterations.

\section{Discussion}

Entire or partial loss of chromosome 10 is a common genetic alteration in a variety of human cancers, including glioblastomas (Albarosa et al, 1996; Fults et al, 1998; Ichimura et al, 1998; Karlbom et al, 1993; Kon et al, 1998; Maier et al, 1997; Rasheed et al, 1995; Sonoda et al, 1996; Voesten et al, 1997), malignant meningiomas (Rempel et al, 1993; Simon et al, 1995), endometrial carcinomas (Peiffer et al, 1995), prostate carcinomas (Gray et al, 1995), renal carcinomas (Morita et al, 1991), small cell lung carcinomas (Ried et al, 1994), non-Hodgkin's lymphomas (Speaks et al, 1992), and melanomas (Herbst et al, 1994; Isshiki et al, 1993). In glioblastomas, there appear to be at least three putative tumor suppressor loci, ie, 10p14-pter, 10q23-24, and 10q25-qter (Albarosa et al, 1996; Fults et al, 1998; Ichimura et al, 1998; Karlbom et al, 1993; Kimmelman et al, 1996; Kon et al, 1998; Maier et al, 1997; Rasheed et al, 1995; Sonoda et al, 1996; Voesten et al, 1997). However, little is known whether the frequency and extent of $\mathrm{LOH}$ on chromosome 10 are different between primary and secondary glioblastomas. Ichimura et al (1998) carried out extensive LOH study in 198 astrocytic gliomas and showed that most glioblastomas lost one entire chromosome, while astrocytomas preferentially lost only $10 p$. However, the astrocytomas and glioblastomas that were analyzed were derived from different patients. Using comparative genome hybridization (CGH) analysis, Weber et al (1996) reported that 4 of 10 anaplastic astrocytomas and glioblastomas that had progressed from lowgrade astrocytoma showed a reduced number of chromosome segments on 10q. Recently, we reported that $\mathrm{LOH}$ on 10q25-qter is often associated with abrupt morphologic transition from low-grade or anaplastic astrocytoma to a highly malignant, undifferentiated glioblastoma phenotype lacking glial fibrillary acidic protein (GFAP) expression (Fujisawa et al, 1999).

The present study is the first to demonstrate unequivocally that LOH\#10 occurs at a similar frequency in primary and secondary glioblastomas but that the patterns of allelic loss are different. Entire loss of chromosome 10 was typical for primary glioblastomas, whereas partial LOH on $10 \mathrm{q}$ was characteristic for secondary glioblastomas. This pattern is consistent with the observation in this and previous studies (Lang et al, 1994; Leenstra et al, 1998; von Deimling et al, 1992) that glioblastomas with EGFR amplification, a genetic hallmark of primary glioblastomas, typically show complete loss of chromosome 10.

Several transformation-associated genes have been identified on 10q, including PTEN at 10q23.3 (Li et al, 
1997; Steck et al, 1997), LGI1 at 10q24 (Chernova et al, 1998), BUB3 at 10q24-q26 (Cahill et al, 1999), MXI1 at 10q25.1 (Eagle et al, 1995), hours-neu at 10q25.1 (Nakamura et al, 1998), abLIM or LIMAB1 at 10q25.1 (Kim et al, 1997; Roof et al, 1997) and DMBT1 at 10q26.1 (Mollenhauer et al, 1997). The PTEN gene, which encodes a protein with homology to the catalytic domain of tyrosine phosphatase and to the cytoskeletal proteins tensin and auxilin ( $\mathrm{Li}$ et al, 1997; Steck et al, 1997), is mutated frequently in glioblastomas (Boström et al, 1998; Chiariello et al, 1998; Duerr et al, 1998; Fults et al, 1998; Maier et al, 1998; Tohma et al, 1998; Wang et al, 1997), prostate carcinomas (Cairns et al, 1997; Suzuki et al, 1998), and endometrial carcinomas (Risinger et al, 1997; Tashiro et al, 1997). We previously reported that mutations in the PTEN gene, which is located on 10q23, are common $(32 \%)$ in primary but rare $(4 \%)$ in secondary glioblastomas (Tohma et al, 1998). DMBT1 is deleted frequently in glioblastomas (Mollenhauer et al, 1997; Somerville et al, 1998) but DMBT1 mutations have not yet been identified. Although growth suppression has been observed after microcell-mediated transfer of chromosome fragments from 10p14-15 into T98G glioblastoma cells (Kon et al, 1998), the putative tumor suppressor gene at this locus has not yet been identified.

The present study suggests that the involvement of different tumor suppressor gene(s) on chromosome 10 is between primary and secondary glioblastoma. Tumor suppressor gene(s) on chromosome 10p may play an important role in the evolution of primary, but not secondary, glioblastomas. Alternatively, the more extensive deletion on chromosome 10 in primary, rather than in secondary glioblastomas may result from greater chromosomal instability in primary glioblastomas. However, little is known about the mechanisms of chromosomal deletion, except for the general assumption that it is probably attributed to chromosomal instability caused by the disruption of mitotic checkpoints (Lengauer et al, 1998) or premature mitosis involving damaged DNA (Paulovich et al, 1997).

In conclusion, this study shows that LOH on chromosome 10 is more extensive in primary glioblastomas, rather than in secondary gliobastomas. Primary glioblastomas are characterized by an entire loss of chromosome 10, whereas in secondary glioblastomas, $\mathrm{LOH}$ is restricted to chromosome $10 \mathrm{q}$, suggesting that different tumor suppressor genes on this chromosome are involved in the development of these glioblastoma subtypes.

\section{Materials and Methods}

\section{Tumor and Blood Samples}

Seventeen primary and 13 secondary glioblastomas were obtained from the patients operated on in the Department of Neurosurgery, University Hospital, Zürich, Switzerland. All patients with primary glioblastoma had a clinical history of $<3$ months and did not show any histologic or radiologic evidence of a pre- cursor lesion, whereas all patients with secondary glioblastoma had surgeries for low-grade astrocytoma $>6$ months before the second operation for glioblastoma. Seventeen patients were men and 13 were women (Table 1). Tumors were fixed in formalin, embedded in paraffin for routine histopathologic analysis, and were classified according to the WHO grading system (Kleihues et al, 1993).

For all primary glioblastomas and two secondary glioblastomas (cases 72 and 295), aliquots of tumors were frozen immediately in liquid nitrogen and stored at $-80^{\circ} \mathrm{C}$ until DNA extraction. Genomic DNA was extracted using TRIZOL Reagent (GIBCO BRL, Cergy Parroise, France) according to the manufacturer's instructions. Matched peripheral blood samples of these cases were obtained and DNA was extracted using QIAamp DNA Blood Kit (QIAGEN, Courtaboeuf, France).

For the cases in which frozen tissues were not available (low-grade astrocytoma and secondary glioblastomas, except for cases 72 and 295), DNA was extracted from paraffin sections (Brüstle et al, 1992; Fujisawa et al, 1999). In two secondary glioblastomas (cases 57 and 68), DNA was also extracted from the peritumoral brain tissue in paraffin sections. In case 72, DNA was extracted from paraffin-embedded, lowgrade astrocytoma, frozen glioblastoma, and blood samples.

\section{Analysis of $\mathrm{LOH}$ on Chromosome 10}

$\mathrm{LOH}$ on chromosome 10 was studied by PCR-based microsatellite analysis (Fujisawa et al, 1999). Twentyeight microsatellite loci were selected to cover chromosome 10, including reported common deletions on 10p14-pter (Ichimura et al, 1998; Karlbom et al, 1993; Kimmelman et al, 1996; Kon et al, 1998; Sonoda et al, 1996; Voesten et al, 1997), 10q23-24 (Albarosa et al, 1996; Fults et al, 1998; Ichimura et al, 1998; Karlbom et al, 1993; Maier et al, 1997; Rasheed et al, 1995; Sonoda et al, 1996), and 10q25-qter (Albarosa et al, 1996; Fults et al, 1998; Ichimura et al, 1998; Karlbom et al, 1993; Maier et al, 1997; Rasheed et al, 1995; Sonoda et al, 1996). All microsatellite markers were purchased from Research Genetics (Huntsville, AL); all were dinucleotide repeats, except for D10S1435 (tetranucleotide repeats). The size range and heterozygosity of each marker were obtained from the Genome Database (http://gdbwww.gdb.org/). The genetic map and distances of chromosome 10 were obtained from the enhanced location database at ftp://cedar.genetics.soton.ac.uk/pub/chrom 10/gmap (Collins et al, 1996).

For all primary glioblastomas and two secondary glioblastomas, DNA from peripheral blood samples from the same patient was used as a reference, whereas for secondary glioblastomas except for two cases, DNA samples from low-grade astrocytoma from the respective patients were used as a reference. After PCR amplification, the allelic pattern for each marker was determined by comparing the electrophoretic pattern of DNA from glioblastoma with that of 
reference DNA, ie, blood DNA or DNA samples extracted from low-grade astrocytoma. PCR was performed according to the instructions of Research Genetics with minor modifications. Briefly, $10 \mathrm{ng}$ of DNA $(1 \mu \mathrm{l})$ samples of fresh-frozen tumors and blood samples or $1 \mu \mathrm{l}$ of DNA solution from paraffin sections were subjected to PCR with $2 \mu$ of $5 \times$ PCR buffer, $200 \mu \mathrm{M}$ of each dNTP, 6 pmol of each sense and antisense primer, $1 \mu \mathrm{Ci}$ of $\left[\alpha^{-}{ }^{33} \mathrm{P}\right]-\mathrm{dCTP}$ (ICN Biomedicals, specific activity $3000 \mathrm{Ci} / \mathrm{mmol}), 0.225$ units of Taq polymerase (Sigma Chemical, St. Louis, Missouri), and $1.5 \mathrm{~mm}$ of $\mathrm{MgCl}_{2}$ in a final volume of $10 \mu \mathrm{l}$, with an initial denaturation of $95^{\circ} \mathrm{C}$ for 2 minutes, followed by 30 cycles (DNA from frozen tumors and blood sample) or 35 cycles (DNA from paraffin sections) of denaturation at $94^{\circ} \mathrm{C}$ for 45 seconds, annealing at $57^{\circ} \mathrm{C}$ for 45 seconds and polymerization at $72^{\circ} \mathrm{C}$ for 1 minute, and a final extension at $72^{\circ} \mathrm{C}$ for 7 minutes, using a Genius DNA Thermal Cycler (Techne, Cambridge, United Kingdom). PCR products were mixed with an equivalent volume of the denaturing solution containing 95\% formamide, $20 \mathrm{~mm}$ EDTA, 0.05\% xylene cyanol, and $0.05 \%$ bromophenol blue. Immediately after heating at $95^{\circ} \mathrm{C}$ for 5 minutes, $4 \mu \mathrm{l}$ of the mixture was loaded onto a $7 \%$ polyacrylamide/7 $\mathrm{M}$ of urea sequencing gel. Gels were run at 70 watts $(\mathrm{W})$ for 3 to 6 hours, dried at $80^{\circ} \mathrm{C}$, and autoradiographed for 24 to 96 hours. Gels were also exposed to Storage Phosphor screens (Molecular Dynamics, Sunnyvale, California). LOH was scored when signal intensity was reduced in glioblastoma by $>50 \%$ of reference DNA, which was measured by densitometry (Bio-Rad model GS-670) or by a Phosphorimager (Molecular Dynamics).

\section{Other Genetic Alterations}

The genetic alterations in secondary glioblastomas, except for two cases, were reported previously (Tohma et al, 1998; Watanabe et al, 1996) (Table 1). For all primary glioblastomas and two cases of secondary glioblastomas (cases 72 and 295), the following genetic analyses were carried out.

PCR-SSCP Analysis and Direct DNA Sequencing for p53 and PTEN Mutations. Prescreening for mutations by PCR-SSCP analysis was carried out, as previously described in exons 5-8 of the p53 gene (Watanabe et al, 1996) and in exons 1-9 of the PTEN gene (Reis et al, 1999; Tohma et al, 1998; Watanabe et al, 1998). Samples which showed mobility shifts in the SSCP gels were further analyzed by direct DNA sequencing (Reis et al, 1999; Tohma et al, 1998; Watanabe et al, 1996).

Differential PCR for EGFR Amplification. To detect EGFR amplification, differential PCR was carried out, using the cystic fibrosis (CF) gene as a reference (Hunter et al, 1995), with some modifications (Tohma et al, 1998). The mean EGFR/CF ratio, using normal blood DNA sampling, was 1.11 with a standard variation of 0.11. An EGFR/CF ratio $>2.6$ was regarded as evidence of EGFR amplification (Rollbrocker et al, 1996). One primary glioblastoma, which showed
EGFR amplification in our previous study (Tohma et al, 1998), was used as a positive control.

\section{Statistical Analyses}

Fisher's exact test was carried out to analyze the contingency table for frequency of EGFR amplification, p53 and PTEN mutations, and LOH\#10 between primary and secondary glioblastomas.

\section{Acknowledgements}

This study was supported by a grant from the Foundation for Promotion of Cancer Research, Japan.

\section{References}

Albarosa R, Colombo BM, Roz L, Magnani I, Pollo B, Cirenei N, Giani C, Conti AMF, DiDonato S, and Finocchiaro G (1996). Deletion mapping of gliomas suggests the presence of two small regions for candidate tumor-suppressor genes in a 17-cM interval on chromosome 10q. Am J Hum Genet 58:1260-1267.

Boström J, Cobbers JMJL, Wolter M, Tabatabai G, Weber RG, Lichter P, Collins VP, and Reifenberger G (1998). Mutation of the PTEN (MMAC1) tumor suppressor gene in a subset of glioblastomas but not in meningiomas with loss of chromosome arm 10q. Cancer Res 58:29-33.

Brüstle O, Ohgaki H, Schmitt HP, Walter GF, Ostertag H, and Kleihues $P$ (1992). Primitive neuroectodermal tumors after prophylactic central nervous system irradiation in children. Association with an activated K-ras gene. Cancer 69:23852392.

Cahill DP, da Costa LT, Carson-Walter EB, Kinzler KW, Vogelstein B, and Lengauer C (1999). Characterization of MAD2B and other mitotic spindle checkpoint genes. Genomics 58:181-187.

Cairns P, Okami K, Halachmi S, Halachmi N, Esteller M, Herman JG, Jen J, Isaacs WB, Bova GS, and Sidransky D (1997). Frequent inactivation of PTEN/MMAC1 in primary prostate cancer. Cancer Res 57:4997-5000.

Chernova OB, Somerville RPT, and Cowell JK (1998). A novel gene, $L$ Gl1, from 10q24 is rearranged and downregulated in malignant brain tumors. Oncogene 17:2873-2881.

Chiariello E, Roz L, Albarosa R, Magnani I, and Finocchiaro G (1998). PTEN/MMAC1 mutations in primary glioblastomas and short-term cultures of malignant gliomas. Oncogene 16:541-545.

Collins A, Frezal J, Teague J, and Morton NE (1996). A metric map of humans: $23: 500$ loci in 850 bands. Proc Natl Acad Sci U S A 93:14771-14775.

Duerr EM, Rollbrocker B, Hayashi Y, Peters N, Meyer-Puttlitz B, Louis DN, Schramm J, Wiestler OD, Parsons R, Eng C, and von Deimling A (1998). PTEN mutations in gliomas and glioneuronal tumors. Oncogene 16:2259-2264.

Eagle LR, Yin X, Brothman AR, Williams BJ, Atkin NB, and Prochownik EV (1995). Mutation of the MXI1 gene in prostate cancer. Nat Genet 9:249-255.

Fujisawa $\mathrm{H}$, Kurrer M, Reis RM, Yonekawa $\mathrm{Y}$, Kleihues $\mathrm{P}$, and Ohgaki H (1999). Acquisition of the glioblastoma phenotype during astrocytoma progression is associated with $\mathrm{LOH}$ on chromosome 10q25-qter. Am J Pathol 155:387-394. 
Fults D, Pedone CA, Thompson GE, Uchiyama CM, Gumpper KL, lliev D, Vinson VL, Tavtigian SV, and Perry III WL (1998). Microsatellite deletion mapping on chromosome $10 \mathrm{q}$ and mutation analysis of MMAC1, FAS, and MXI1 in human glioblastoma multiforme. Int J Oncol 12:905-910.

Galanis E, Buckner JC, Dinapoli RP, Scheithauer BW, Jenkins RB, Wang CH, O'Fallon JR, and Farr G Jr (1998). Clinical outcome of gliosarcoma compared with glioblastoma multiforme: North Central Cancer Treatment Group results. J Neurosurg 89:425-430.

Gray IC, Phillips SMA, Lee SJ, Neoptolemos JP, Weissenbach J, and Spurr NK (1995). Loss of the chromosomal region 10q23-25 in prostate cancer. Cancer Res 55:48004803.

Herbst RA, Weiss J, Ehnis A, Cavenee WK, and Arden KC (1994). Loss of heterozygosity for 10q22-10qter in malignant melanoma progression. Cancer Res 54:3111-3114.

Hunter SB, Abbott K, Varma VA, Olson JJ, Barnett DW, and James CD (1995). Reliability of differential PCR for the detection of EGFR and MDM2 gene amplification in DNA extracted from FFPE glioma tissue. J Neuropathol Exp Neurol 54:57-64.

Ichimura K, Schmidt EE, Miyakawa A, Goike HM, and Collins VP (1998). Distinct patterns of deletion on $10 p$ and $10 q$ suggest involvement of multiple tumor suppressor genes in the development of astrocytic gliomas of different malignancy grades. Genes Chromosomes Cancer 22:9-15.

Isshiki K, Elder DE, Guerry D, and Linnenbach AJ (1993). Chromosome 10 allelic loss in malignant melanoma. Genes Chromosomes Cancer 8:178-184.

Karlbom AE, James CD, Boethius J, Cavenee WK, Collins VP, Nordenskjöld M, and Larsson C (1993). Loss of heterozygosity in malignant gliomas involves at least three distinct regions on chromosome 10. Hum Genet 92:169-174.

Kim AC, Peters LL, Knoll JHM, van Huffel C, Ciciotte SL, Kleyn PW, and Chishti AH (1997). Limatin (LIMAB1), an actin-binding LIM protein, maps to mouse chromosome 19 and human chromosome $10 \mathrm{q} 25$, a region frequently deleted in human cancers. Genomics 46:291-293.

Kimmelman AC, Ross DA, and Liang BC (1996). Loss of heterozygosity of chromosome 10p in human gliomas. Genomics 34:250-254.

Kleihues P, Burger PC, and Scheithauer BW, editors (1993). Histological typing of tumours of the central nervous system. In: World Health Organization international histological classification of tumours. New York, Berlin, Heidelberg: Springer Verlag.

Kleihues $\mathrm{P}$ and Ohgaki H (1999). Primary and secondary glioblastomas: From concept to clinical diagnosis. NeuroOncology 1:44-51.

Kon $\mathrm{H}$, Sonoda $\mathrm{Y}$, Kumabe $\mathrm{T}$, Yoshimoto $\mathrm{T}$, Sekiya $\mathrm{T}$, and Murakami Y (1998). Structural and functional evidence for the presence of tumor suppressor genes on the short arm of chromosome 10 in human gliomas. Oncogene 16:257-263.

Lang FF, Miller DC, Koslow M, and Newcomb EW (1994). Pathways leading to glioblastoma multiforme: A molecular analysis of genetic alterations in 65 astrocytic tumors. J Neurosurg 81:427-436.

Lantos PL, VandenBerg SR, and Kleihues P (1996). Tumours of the nervous system. In: Graham DI and Lantos PL, editors. Greenfield's neuropathology. London: Arnold, 583-879.
Leenstra S, Oskam NT, Bijleveld EH, Bosch DA, Troost D, and Hulsebos TJM (1998). Genetic sub-types of human malignant astrocytoma correlate with survival. Int $\mathrm{J}$ Cancer 79:159-165.

Lengauer C, Kinzler KW, and Vogelstein B (1998). Genetic instabilities in human cancers. Nature 396:643-649.

Li J, Yen C, Liaw D, Podsypanina K, Bose S, Wang SI, Puc J, Miliaresis C, Rodgers L, McCombie R, Bigner SH, Giovanella BC, Ittmann $\mathrm{M}$, Tycko $\mathrm{B}$, Hibshoosh $\mathrm{H}$, Wigler $\mathrm{MH}$, and Parsons R (1997). PTEN, a putative protein tyrosine phosphatase gene mutated in human brain, breast, and prostate cancer. Science 275:1943-1947.

Maier D, Comparone D, Taylor E, Zhang Z, Gratzl O, Van Meir EG, Scott RJ, and Merlo A (1997). New deletion in low-grade oligodendroglioma at the glioblastoma suppressor locus on chromosome 10q25-26. Oncogene 15:997-1000.

Maier D, Zhang Z, Taylor E, Hamou MF, Gratzl O, Van Meir EG, Scott RJ, and Merlo A (1998). Somatic deletion mapping on chromosome 10 and sequence analysis of PTEN/MMAC1 point to the $10 \mathrm{q} 25-26$ region as the primary target in lowgrade and high-grade gliomas. Oncogene 16:3331-3335.

Mollenhauer J, Wiemann S, Scheurlen W, Korn B, Hayashi Y, Wilgenbus KK, von Deimling A, and Poustka A (1997). $D M B T 1$, a new member of the SRCR superfamily, on chromosome $10 \mathrm{q} 25.3-26.1$ is deleted in malignant brain tumours. Nat Genet 17:32-39.

Morita R, Saito S, Ishikawa J, Ogawa O, Yoshida O, Yamakawa K, and Nakamura $Y$ (1991). Common regions of deletion on chromosomes $5 \mathrm{q}, 6 \mathrm{q}$, and $10 \mathrm{q}$ in renal cell carcinoma. Cancer Res 51:5817-5820.

Moschonas NK, Spurr NK, and Mao J (1996). Report of the first international workshop on human chromosome 10 mapping 1995. Cytogenet Cell Genet 72:99-112.

Nakamura $\mathrm{H}$, Yoshida M, Tsuiki H, Ito K, Ueno M, Nakao M, Oka K, Tada M, Kochi M, Kuratsu J, Ushio Y, and Saya $H$ (1998). Identification of a human homolog of the Drosophila neuralized gene within the 10q25.1 malignant astrocytoma deletion region. Oncogene 16:1009-1019.

Paulovich AG, Toczyski DP, and Hartwell LH (1997). When checkpoints fail. Cell 88:315-321.

Peiffer SL, Herzog TJ, Tribune DJ, Mutch DG, Gersell DJ, and Goodfellow PJ (1995). Allelic loss of sequences from the long arm of chromosome 10 and replication errors in endometrial cancers. Cancer Res 55:1922-1926.

Rasheed BKA, McLendon RE, Friedman HS, Friedman AH, Fuchs HE, Bigner DD, and Bigner SH (1995). Chromosome 10 deletion mapping in human gliomas: A common deletion region in 10q25. Oncogene 10:2243-2246.

Reis RM, Konu-Lebleblicioglu D, Lopes JM, Kleihues P, and Ohgaki H (In Press, 1999). Genetic profile of the gliosarcoma. Am J Pathol

Rempel SA, Schwechheimer K, Davis RL, Cavenee WK, and Rosenblum ML (1993). Loss of heterozygosity for loci on chromosome 10 is associated with morphologically malignant meningioma progression. Cancer Res 53:2386-2392.

Ried T, Petersen I, Holtgreve-Grez H, Speicher MR, Schröck E, du Manoir S, and Cremer T (1994). Mapping of multiple DNA gains and losses in primary small cell lung carcinomas by comparative genomic hybridization. Cancer Res 54:18011806. 
Risinger JI, Hayes AK, Berchuck A, and Barrett JC (1997). PTEN/MMAC1 mutations in endometrial cancers. Cancer Res 57:4736-4738.

Rollbrocker B, Waha A, Louis DN, Wiestler OD, and von Deimling A (1996). Amplification of the cyclin-dependent kinase 4 (CDK4) gene is associated with high cdk4 protein levels in glioblastoma multiforme. Acta Neuropathol 92:7074.

Roof DJ, Hayes A, Adamian M, Chishti AH, and Li T (1997). Molecular characterization of abLIM, a novel actin-binding and double zinc finger protein. J Cell Biol 138:575-588.

Simon M, von Deimling A, Larson JJ, Wellenreuther R, Kaskel P, Waha A, Warnick RE, Tew JM, and Menon AG (1995). Allelic losses on chromosomes 14:10, and 1 in atypical and malignant meningiomas: A genetic model of meningioma progression. Cancer Res 55:4696-4701.

Somerville RPT, Shoshan Y, Eng C, Barnett G, Miller D, and Cowell JK (1998). Molecular analysis of two putative tumour suppressor genes, PTEN and DMBT, which have been implicated in glioblastoma multiforme disease progression. Oncogene 17:1755-1757.

Sonoda $\mathrm{Y}$, Murakami $\mathrm{Y}$, Tominaga $\mathrm{T}$, Kayama T, Yoshimoto $\mathrm{T}$, and Sekiya T (1996). Deletion mapping of chromosome 10 in human glioma. Jpn J Cancer Res 87:363-367.

Speaks SL, Sanger WG, Masih AS, Harrington DS, Hess M, and Armitage JO (1992). Recurrent abnormalities of chromosome bands 10q23-25 in non-Hodgkin's lymphoma. Genes Chromosomes Cancer 5:239-243.

Steck PA, Pershouse MA, Jasser SA, Yung WKA, Lin $\mathrm{H}$, Ligon $\mathrm{AH}$, Langford LA, Baumgard ML, Hattier T, Davis $\mathrm{T}$, Frye C, Hu R, Swedlund B, Teng DHF, and Tavtigian SV (1997). Identification of a candidate tumour suppressor gene, MMAC1, at chromosome 10q23.3 that is mutated in multiple advanced cancers. Nat Genet 15:356-362.

Suzuki H, Freije D, Nusskern DR, Okami K, Cairns P, Sidransky D, Isaacs WB, and Bova GS (1998). Interfocal heterogeneity of PTEN/MMAC1 gene alterations in multiple metastatic prostate cancer tissues. Cancer Res 58:204-209.
Tashiro H, Blazes MS, Wu R, Cho KR, Bose S, Wang SI, Li J, Parsons R, and Ellenson LH (1997). Mutations in PTEN are frequent in endometrial carcinoma but rare in other common gynecological malignancies. Cancer Res 57:3935-3940.

Tohma Y, Gratas C, Biernat W, Peraud A, Fukuda M, Yonekawa Y, Kleihues P, and Ohgaki H (1998). PTEN (MMAC1) mutations are frequent in primary glioblastomas (de novo) but not in secondary glioblastomas. J Neuropathol Exp Neurol 57:684-689.

Voesten AMJ, Bijleveld EH, Westerveld A, and Hulsebos TJM (1997). Fine mapping of a region of common deletion on chromosome arm 10p in human glioma. Genes Chromosomes Cancer 20:167-172.

von Deimling A, Louis DN, von Ammon K, Petersen I, Hoell T, Chung RY, Martuza RL, Schoenfeld DA, Yasargil MG, Wiestler OD, and Seizinger BR (1992). Association of epidermal growth factor receptor gene amplification with loss of chromosome 10 in human glioblastoma multiforme. J Neurosurg 77:295-301.

Wang SI, Puc J, Li J, Bruce JN, Cairns P, Sidransky D, and Parsons R (1997). Somatic mutations of PTEN in glioblastoma multiforme. Cancer Res 57:4183-4186.

Watanabe K, Peraud A, Gratas C, Wakai S, Kleihues P, and Ohgaki H (1998). p53 and PTEN gene mutations in gemistocytic astrocytomas. Acta Neuropathol 95:559-564.

Watanabe K, Tachibana O, Sato K, Yonekawa Y, Kleihues P, and Ohgaki H (1996). Overexpression of the EGF receptor and $p 53$ mutations are mutually exclusive in the evolution of primary and secondary glioblastomas. Brain Pathol 6:217224.

Weber RG, Sabel M, Reifenberger J, Sommer C, Oberstrasse J, Reifenberger G, Kiessling M, and Cremer T (1996). Characterization of genomic alterations associated with glioma progression by comparative genomic hybridization. Oncogene 13:983-994. 